\title{
Communication and Innovation in the Performance of Weaving and Pottery Crafts in Gojjam, Ethiopia, Wondifraw Mihret Dessie, Wondemihret2009@gmail.com, Gojjam Ademe Mengistu, Gademe@gmail.com, Tigist Abera Mulualaem, Tabera72@yahoo.com
}

Wondifraw Mihret Dessie ( $\square$ wondemihret2009@gmail.com )

Debre Markos University

Dr. Gojjam Mengistu

Bahir Dar University

Tigist Mulualem

Debre Markos University College of Social Science and Humanity

\section{Research}

Keywords: business performance, communication, craft industries, innovation, pottery, strategic communication, weaving

Posted Date: March 23rd, 2021

DOI: https://doi.org/10.21203/rs.3.rs-311354/v1

License: (1) (1) This work is licensed under a Creative Commons Attribution 4.0 International License. Read Full License 


\section{Abstract}

Competitive organizations harness information and knowledge sharing undertakings to take risks and break customary routines. This study investigates craftspeople's communication practices and innovation implementation towards improving business performance. Cross-sectional survey research design was employed to describe and see the association of communication and innovation with business performance. Data were collected from a sample of 326 craftspeople through structured questionnaire and field observation. Both descriptive and SEM statistics were mainly used to analyze data. Findings revealed that communication practices vital for craftspeople to be innovative and integrate them with clients were negligible. The communication flaws in turn resulted in stagnant and in-house limited trifling inventiveness in craft industries. Moreover, reflexivity, frequency of communication on creativity, product and market innovations were significantly associated with craftspeople's performance. Hence, it is recommended to arrange training and experience sharing schemes for craftspeople to enhance their communication and innovation skills thereby improve performance.

\section{Introduction}

The revival of interest in craft industries has made indigenous craft a culturally and economically important sector all over the world (Dubois, 2008; Zhan et al., 2017). These industries are pioneers to exploit local knowledge and preserve culture through diffusion of socioculturally shaped innovative crafts. These are used by the society revealing tacit knowledge which contributes to innovative cultural practices (Lin \& Chen, 2012; Eisenberg \& Gerlach, 2006). According to United Nations Industrial Development Organization [UNIDO] (2002), craft industries apply creativity, cultural knowledge and indigenous intellectual property to manufacture products and provide services conforming to sociocultural needs.

Sharing these cultural products and learning from such innovative ways of production among craftspeople and the society at large foster the development of cultural industries (Croes \& Vanegas, 1998; Wherry, 2008; Livingstone et al., 2009; Grobar, 2017). This aligns with diffusion of innovation theory which interlaces communication, invention, and social system (Naqshbandi \& Kaur, 2015). Social theory of innovation partially explains the former theory, and appropriately frames this study by associating innovation and communication in an evolutionary practice of sharing innovation through strategic communication (Zerfass \& Huck, 2007).

Innovation and information exchange are decisive for performance in cultural industries that traditionally put aside strategic routines, procedures and methods for new things (Zerfass, 2018). In the development of craft industries, innovation has principal importance to create economic values leading to competitiveness (Hartley, 2007; Fidler \& Johnson, 1984). Craft industries are recognized as sources of indigenous creativity pertinent to the development of emerging industries (Hartley, 2007; Vinodrai \& Gertler, 2006). Implementing innovation by linking craft industries and emerging large industries requires acknowledging the contribution of indigenous knowledge, experiencing creative orientations and 
employing purposeful communication. This hence attributes to realization of market orientated and identity driven innovation implementation among craft industries as hybrid innovation links local creativity with novel approaches of emerging industries.

Ethiopia has been undoubtedly the most important center for production of handmade cloth in Eastern Africa, and has always held this position of supremacy which may contribute innovative craft products (Spring and Hudson, 1995). Though there are limited sources, the stylistic comparisons of some ceramics craft products in Iran were taken probably from Ethiopia or more generally from north-eastern Africa (Mugavero \& Vidale, 2006). In Ethiopia, indigenous industries have become the socio-cultural and historical reflections of the society attributing to development so that various efforts are exerted to sustain them by improving their performance (Embassy of Japan in Ethiopia, EoJE, 2007). Dubois's (2008) exploration of Ethiopian traditional crafts also confirmed as most Ethiopians were historically selfsufficient and the average household provided its raw materials through the transfer of original craft works. Weaving and pottery craft industries produce various kinds of handicrafts unique in history, tradition, and culture evolved by the various people of the country, Ethiopia (EoJE, 2007). Wayessa (2011) found that earliest archaeological research in southwestern Ethiopia yield ceramic data in which pots were discovered along with ground-stone hoes. Other studies revealed the extent that the earliest pottery came from northern highlands of Ethiopia three centuries ago (Finneran, 2007; Phillipson, 2005). These all depict that the Ethiopian craft has magnificent contribution in the development of weaving and pottery crafts.

In this regard, the Amhara Region, which this study focused, has the largest share in the establishments of (about 82,572) traditional textile industries (Ethiopian Central Statistics Agency [ECSA], 2007) . The abundance of weaving craft industries in Gojjam has attributed to this. The weaving and pottery craft making traditional practice in Gojjam, alike other localities, (Dubois, 2008), donates for craft innovation.

The development of craft industries in Gojjam, however, seemed declining as it is chiefly operated at family level and the products tend to fail satisfying needs. Though craft related indigenous tacit knowledge and skills attribute to innovation, the craft labor has been socially and politically neglected (Banks, 2010; Sennett, 2008; Grobar, 2017). The contribution of craft industries to emerging industries, the relevance of links with craftspeople and the non-craftspeople tend very limited. Due to information unavailability (Peeters, 2010) and complicated consumer behavior (Messele, 2013), these crafts become incompetence to break new markets.

Most studies on the international craft sector focused on the relevance of strategic communication (Zerfass \& Huck, 2007; Hirst and Mann, 2004; MdSaad et al, 2014; Kotelnikova, 2014) and innovation implementation (Kilic et al., 2015) at technology and finance intensive industries. Very few studies were conducted on the Ethiopian craft sector. Girum (2011) and EoJE (2007) revealed that indigenous knowledge of weavers at Shiro Meda, Dorze Community, Southern Ethiopia contributed to fashion design and modern textile technology, but constraints in quality affected its economic outcome. Hofverberg (2010) also confirmed that weaving craft at Dorze district offers new insights for the prosperity of 
traditional handicraft. These studies emphasized the economic contribution and determinants of craft industries in the southern and central part of Ethiopia.

The weaving and pottery crafts in north western and eastern part of Ethiopia were not studied yet. In addition, investigating communication practices, innovation implementation and their interplay with craftspeople's performance were overlooked. Hence, this investigation has theoretical and practical insights to the theory of strategic communication and innovation in the continuum of craft industries. This would contribute to the development of related industries and associated policy issues in the implementation of evolutionary and revolutionary approaches.

\section{Theories of Innovation}

The innovation theory has been viewed from business enterprise development perspective addressing product, process, marketing and organizational attributes (Organization for Economic Co-operation and Development [OECD], 2005; Kilic et al., 2015). Implementing innovations by diffusing through mediated and /or interpersonal communication approaches is valued in innovation diffusion theory (Backer \& Rodgers, 1998). It has aspects of invention, communication channel, and social system (Naqshbandi \& Kaur, 2015). This implies the implementation of appropriate communication strategy to result in effective innovation outputs and holistic development.

Social theory has brought the most relevant link between innovation and communication (Zerfass \& Huck, 2007). The performance of craftspeople at various levels has been influenced by their inventiveness which emanates out of employing strategic communication. Theories of innovation generally account revolutionary and evolutionary principles in product and process aspects of creativity. Incremental innovation as one aspect of evolutionary principles is built on existing knowledge and enhancing competency to leverage knowledge and resources (Naqshbandi \& Kaur, 2015). Open innovation theory similarly deals within and outside interactive practices benefiting from external and internal sources and ideas as an evolutionary practice of sharing ideas. On the contrary, the revolutionary implementation of innovation is technology intensive attempt (ibid) which can be associated with the creation of new market and value networks eventually disrupting the existing market. Closed innovations in this respect engage employees to create their own ideas and win competitors which cannot access ideas.

\section{Communication and Innovation}

Communication as a strategy of sharing and integrating new knowledge or information to create novel products within an industry and with other related industries is a means of survival and sustained success (Zerfass et al., 2018). Communication is a crucial part for passing on the innovative spirit within the organization and to every single employee (Zerfass \& Huck, 2007). In participatory approaches, the role of indigenous knowledge, democratization and participation at all levels are stressed as predictors of communication and innovation implementation. Learning from the community is one of the basic principles of participatory communication strategy (Tufte \& Mefalopus, 2009). 
In cultural industries system, creative production and managerial subsystems comprised of communication subsystem gatekeepers as a process of filtering new ideas (Lin and Chen, 2012). Since the core product of innovation activities is knowledge, and this new knowledge can only be created through interaction between specialists. With varying backgrounds of expertise, communication is pivotal cement for innovation activities (Zerfass \& Huck, 2007). Strategic communication concentrates on the core drivers of organizational success, and innovation is an integral part of strategic communication (Zerfass \& Huck, 2007).

Hirst and Mann (2004) state that communication is an effective mechanism to translate, share and integrate new information into commercial products or processes. Communication practices are operationalized as team boundary-spanning, communication safety, team reflexivity and task communication (Hirst and Mann, 2004; MdSaad et al, 2014). They state boundary spanning as it is sharing information by linking with internal and external groups while communication safety focuses on the positive contribution of the members to innovation without any threat. Reflexivity is what members know about the actual working environment, the development of new understanding and the level of collaboration. The last component of this model, task communication, considers clarity and goal sharing among group members. Hirst and Mann (2004) found that team communication predicted innovation of project performance. Communication in craft teams has been examined based on communication media richness and communication frequency (Leenders et al., 2003). Hence, the frequency of communication has become the first and foremost explanatory variable of all aspects of team performance.

The nature of information transmitted can be viewed from access and channel perspectives. The type of information, its power and how this information helps to operationalize innovation are related to access category, and the latter points to interpersonal and mediated channels. Sarat (2016) considers that specialized and refined craft skills are needed, but broader communication skills are just crucial to appreciate and understand other subjects and disciplines. Successful collaboration at all stages of creation, promotion and mainstreaming of innovation determines the strategy of innovative communication (Chadwick, 2013). Functions of innovators and recipients in the process of interaction and free communication with use of various associative and illocutionary acts contribute to the creation, advancement and use of innovative products (Kotelnikova, 2014).

The activities of innovation occur in a social context that creative people, who are ostensibly working alone, benefit from social support and recognition. In other cases, creativity stems from people working in pairs, teams, partnerships and networks which require communication. The aim of scientific innovation discourse is to arouse the recipient interest to innovation by describing the whole sphere of the parties, and change the attitude of other competing innovations that have impacts on the choice of communicative strategy (Kotelnikova, 2014).

The establishment of craft industries roots itself to the coexistence of various craftspeople whose innovative values are communicated among different social groups. Associated craft industries are the outcomes of indigenous knowledge and socio-cultural practices addressing the cultural and economic 
demands of one's society for centuries. A tacitly owned socio-technology that craftspeople acquired and habituated is taken as a base to theorize craft innovation (Mamidipudi, 2016). Innovation resulted from the interconnection between science, business and education form knowledge-intensive product whose creation, sale, and consumption require the support of communication. The most commonly identified impacts of innovation are the transition of an idea through successful product development, and the improvement of capabilities and skills Klynveld Peat Marwick Goerdeler (KPMG, 2016).

\section{Innovation implementation in crafts}

Innovation is a strategic tool for firms to survive and gain competitive advantages in the global market (Karabulutu, 2015). The collaboration between different industries significantly contributes to the sustainability of innovation. Craft and creative industries have paramount contribution for product innovation. For example, companies with stronger links with emerging industries are more likely to introduce novel products (KPMG, 2016). Therefore, collaboration with craft industries contributes for both an individual firm and other industries. Innovation through craft is nothing new as its processes have always driven breakthroughs that have passed into other fields (KPMG, 2016). They constitute an indispensable component of corporate strategies to apply more productive manufacturing processes, perform better in the market, seek positive reputation in customers' perception and gain sustainable competitive advantage, as a result ( Gunday et al, 2011).

Craft innovation refers to evolution of techniques, discovery of new materials and application of new tools which catalyze innovation elsewhere. It concerns the spillover effects of craft into other industries (KPMG, 2016). The emphasis given either to conform to cultural values or to merely secure product quality, for competitive advantage, has become controversial in the practice of craft development. According to Banks (2010), dichotomies on inducing market oriented or identity driven innovations often challenge attempts in cultural craft advancements. The innovations in craft industries through evolutionary and /or revolutionary implementations are skeptically argued in the development of indigenous industries (Shumetie and Mihret, 2020). By incorporating modern designs, these crafts are appealing to a wider market and can fetch significantly higher prices, as luxury buyers search for modern products with a unique, artisanal quality (Grobar, 2017). Modern manufacturing for global markets tends to homogenize material culture through its centralized production and divisive production process. In contrast, craft practices usually have a strong local identity through their application of holistic crafting practices, context-based knowledge, culturally specific responses and community-centered production (Zhan et al, 2017). Interlocking craft and emerging industries for mutual benefit by harnessing innovation and communication strategies may crucially settle this argument. Sustaining innovative practices among craftspeople can be attained when information sharing is strategically maintained (Peeters, 2010; Fidler\& Johnson, 1984). This revealed that strategic communication has fundamental contribution for the acceptance of innovation and to reduce complexities in the process of assimilating new practices in a resource constrained organizational system. Craft fused with emerging technological and engineering thinking generates cross-sector innovation and adds substantial value (KPMG, 2016). 
Therefore, craft-related knowledge and skills can be used strategically to stimulate creativity, spearhead innovation, and generate economic value and new employment opportunities. These seek to shed light on how they can be revived not as cultural instances to be safeguarded but as important sources of competitive advantage. With increasing demand for cultural products, (Chunlei et al., 2018), applying specific cultural knowledge to product design has emerged as a desirable technique in designers, where the design itself is considered as an impetus for cultural development (Lin, 2007). Thus, innovation significantly influences performance and its role in the craft sector is invaluable.

\section{Research Questions}

1. How do the craftspeople communicate within and out to share innovative ideas?

2. To what extent do the craftspeople implement innovation in their craft industries?

3. Which attributes of communication practices and innovation implementation are significantly associated with the performance of craftspeople?

\section{Methods}

\section{Research Design}

This study employed cross-sectional survey with mixed research concurrent approach to answer the basic research questions. The study investigated the communication practices and innovation implementation of craftspeople in Gojjam using descriptive analysis. In addition, the association of communication and innovation with the performance of craftspeople was examined using explanatory research design. Further explorations and descriptions were made on the nature of craft products in relation to the communication practices and innovation implementation of the craftspeople based on insights from field observation.

\section{Population and Sampling}

The study area covers East and West Gojjam zones in Amhara Region, Ethiopia. The dominant livelihood for most people in this area is agriculture. In addition, weaving, pottery, tannery and smith related craft activities have been used as an alternate means of livelihood for some segment of the society in Gojjam. From these indigenous crafts, weaving and pottery are the predominant handcrafts in this area. Hence, the target groups for this study were craftspeople residing in districts with abundant craft industries in the study area. To this effect, Sekela, Quarit, Debre Elias and Machake/ districts were purposively selected for the study.

Respondents from the target group were selected using simple random sampling technique. Out of 2890 craftspeople residing in these districts, a sample of 352 craftspeople was selected at standard error of \pm 5 $\%$ using Yamane (1967) formula. A total of 326 questionnaires were properly filled and returned at a response rate of $93 \%$. The nature of the craft products and their actual innovation implementation were simultaneously observed for triangulation and further illustration. 


\section{Methods and Procedures}

Structured questionnaire was adapted from standard measurement of Oslo Innovation Manual (OECD, 2005) that Kilic et al. (2015) used to assess the innovation implementation of manufacturing firms. It was adapted to answer the basic research questions related to innovation taking into account the local context of indigenous craft manufacturing. The items used to investigate communication practices among craftspeople and the societies were adapted from Hirst and Mann (2004) and Md-Saad et al. (2014). Items concerning the communication practices of craftspeople were adapted from the questionnaire used to investigate communication among different development teams whose target population ranges from 60-350 sample size. The questionnaire was finally translated into Amharic (local language) customizing it with the local context.

Performance indicators of small enterprises can be measured using the number of employees, net profit, capital and gross revenue (Dessie and Ademe, 2017; World Bank, 2008). However, all performance indicators were not considered in the context of weaving and pottery crafts as the industries are owned at family level whose operators often work on and off. Due to inconsistencies experienced to calculate labor cost in traditional settings, net profit was not used as performance indicator. The gross revenue of craft industries entails the existence of increment and decrement of performance so that we found justifiable to use revenue as a proxy indicator of performance for weaving and pottery craft industries under study. This was technically calculated by multiplying the number of crafts manufactured and sold by sales prices of each item.

The data collection was carried out applying concurrent and multistage procedures. First, the observation of selected craft industries was conducted to have general overview of the research districts and acquired validation insights in formulating the sampling frame. The observation of some industries in four districts was concurrently carried out during the administration of questionnaire.

The data collected through structured questionnaire were analyzed using descriptive and inferential analysis (mean, percentage, standard deviation and SEM). These analyses were used to describe and portray the association between multiple variables under study. Particularly, SEM was employed to perform multiple and accurate estimations of interdependence among variables. The qualitative data were intertwined with the quantitative analysis after the qualitative data were organized and interpreted thematically. From the field observation, the nature of crafts, and their communication and innovation were described; hence, some pictures were taken to portray the crafts.

The reliability and validity of the questionnaire was checked for suitability for analysis using Cronbach's alpha test. Alike the consistency of the original sources, the questionnaire items were found to be highly consistent. Details of the test are shown in Table 1 below.

Table 1 . The reliability of communication and innovation attributes as per research instrument. 


\begin{tabular}{|llll|}
\hline $\begin{array}{l}\text { Latent factor (Cronbach } \\
\text { alpha) }\end{array}$ & Sub-factors & $\begin{array}{l}\text { No of Measurement } \\
\text { Items }\end{array}$ & $\begin{array}{l}\text { Cronbach } \\
\text { Alpha }\end{array}$ \\
\hline $\begin{array}{l}\text { Communication }(\mathrm{a}= \\
0.97)\end{array}$ & Boundary spanning & 2 & 0.692 \\
\hline & Communication safety & 2 & 0.803 \\
\hline & Reflexivity & 3 & 0.85 \\
\hline & Task communication & 2 & 0.706 \\
\hline & $\begin{array}{l}\text { Communication frequency on } \\
\text { creativity }\end{array}$ & 6 & 0.818 \\
\hline Product Innovation & 5 & 0.782 \\
\hline Innovation $(\mathrm{a}=0.895)$ & Process Innovation & 5 & 0.796 \\
\hline & Marketing Innovation & 4 & 0.784 \\
\hline & Organizational Innovation & 6 & 0.685 \\
\hline
\end{tabular}

\section{Findings}

\section{Pottery and Weaving in Gojjam}

Craft industries in Gojjam have long socio-cultural and historical origins representing indigenous practices of producing and using culturally and economically important tangible materials and cloths. Weaving and pottery are quite common and widely distributed practices whose products vary as to local and national requirements. As it is seen in Figure1 below, potters and weavers in Gojjam make crafts which suit the local needs.

Potters often produce incense burners (3.8\%), big and small pots (15\%), cooking appliances (Dist, $2.5 \%)$, baking kitchen (Magedo Kotabi Midija, 9.4\%), stove (6.28\%), griddle (Mitad, 56.6\%) and coffee pot (Jebena, $10.06 \%$ ) from clay soil. The respondents also confirmed as more number of craftspeople was engaged in the production of griddle, big pots and coffee pot owing to the irreplaceable and locally demanded materials. In weaving craft industries, most craftspeople engage themselves in the production of shema and other thread made products as per the cultural and environmental demand. People in Gojjam especially rural farmers have traditional cultural cloths to be worn during ceremonies and holidays (Figure 2).

Thus, gabi, kuta and netela are mainly needed by the local people. In ordinary working days, farmers wear shawls which comfortably protect them from cold and are dirt resistant. In cold days and evenings, they often wear locally called Gojjam-Azenes. The crafts in every indigenous industry are labor intensive and tiresome. Most of the time, members of the family are engaged in the crafting activities instead of hiring someone from the labor market. As it can be seen in Table 2 below, $85 \%$ of weaving and pottery craft industries engaged a maximum of two workers (members of a family), $86.2 \%$ of the craftspeople inherit 
the craft from family while $13.8 \%$ of them got training by various stakeholders. According to Table 2 , weavers have greater mean weekly revenue as compared to potters.

\section{Table 2. Background of each craft sector}

\begin{tabular}{|llllllllllll|}
\hline \multicolumn{10}{|c|}{ Number of Employees(workers) } & \multicolumn{2}{l|}{ Craft learning \&Startup } \\
\begin{tabular}{|l} 
Craft \\
sector
\end{tabular} & 1 & 2 & 3 & 4 & 5 & 10 & $\begin{array}{l}\text { Learnt } \\
\text { From } \\
\text { family }\end{array}$ & $\begin{array}{l}\text { Through } \\
\text { Training }\end{array}$ & $\begin{array}{l}\text { Mean } \\
\text { weekly } \\
\text { revenue }\end{array}$ & $\begin{array}{l}\text { Total } \\
\text { Crafts- } \\
\text { people }\end{array}$ \\
\hline pottery & 138 & 25 & 1 & - & 0 & 0 & 158 & 6 & 482.2453 & 164 \\
weaving & 63 & 57 & 26 & 13 & 2 & 1 & 123 & 39 & 2303.7815 & 162 \\
\hline Total & 201 & 82 & 27 & 13 & 2 & 1 & 281 & 45 & 2786.027 & 326 \\
\hline
\end{tabular}

\section{Communication practices of craftspeople for innovation}

Information sharing practices have pertinent contribution to add creative values to the process of manufacturing crafts. Craftspeople who are engaged in various craft industries need to share creative ideas to and from their counter parts through mediated communication and interpersonal channels manifested at communal market places, neighbors, custodies, social and business gatherings. As it is portrayed in Table 3 below, about 313 craftspeople were interviewed in schedule questionnaire to explain how far they exchange information on creative ways of craft making.

\section{Table 3.Types of Communication employed to exchange information on creativity}

\begin{tabular}{|llc|}
\hline Information they get about creativity & Frequency & $\%$ \\
\hline No communication and information exchange & 140 & 44.7 \\
\hline share limited experience unintentionally & 142 & 45.37 \\
\hline Share information at market places & 5 & 1.6 \\
\hline $\begin{array}{l}\text { Share information from organization: TVET, merchants community, custody, } \\
\text { training, SMES Agency }\end{array}$ & 20 & 6.4 \\
\hline Share from customers feedback & 6 & 1.9 \\
\hline
\end{tabular}

The qualitative data which were thematically presented in Table 3 above revealed that most of the craftspeople did not share ideas in any means. Potters and weavers in most parts of Gojjam reside together. According to $45.4 \%$ of the craftspeople, nevertheless, they had limited experience to unintentionally share novel ideas with their family, neighbors and friends during interaction for their social business. There were no craftspeople who shared innovative ideas from national and international media outlets. 
Craftspeople have drawbacks in sharing creative ideas to and from various industries which in turn influence their performance. The frequency of getting information about creativity and harnessing this information in their crafts by sharing innovative knowledge and skills affect the operation of craft industries. The consistent practices in using interpersonal and mediated communication outlets attributes to the performance of craftspeople. As it is seen in Table 4, weavers' and potters' frequent practice of acquiring information about creativity that suit to their crafts is minimal. The craftspeople internal and external communication practice to share information without any threat and exclusion from members of craft industries and other sister industries has significance to realize inventiveness by spanning boundaries among cultural industries. The extent these craftspeople share ideas in reflexive manner and communicate to accomplish their tasks influences the practice of weaving and pottery crafts towards innovation. Craftspeople proved as their attempt of spanning boundaries by sharing information through internal and external linkages and doing this from different perspectives was negligible.

According to Table 4, the tendency of craftspeople to avoid risks is very limited. This also attributes to the failure of craftspeople in understanding potential problems they often encounter in the practice of becoming creative. This is due to their inability to share useful information which integrally resulted in cross-fertilizing ideas and spanning innovation.

\section{Table 4. Communication practice of craftspeople}

\begin{tabular}{|lllll|}
\hline Descriptive Statistics & \multicolumn{3}{c|}{} \\
\hline Attributes of communication practice & \multicolumn{4}{c|}{ Mean } \\
\cline { 2 - 5 } & $\mathrm{N}$ & Value & Std. Error \\
\hline Communication frequency & 319 & 1.6108 & .02944 & .52581 \\
\hline Boundary spanning & 320 & 1.7156 & .04016 & .71837 \\
\hline Communication safety & 319 & 1.6348 & .03955 & .70645 \\
\hline Reflexivity & 318 & 1.7683 & .04175 & .74451 \\
\hline Task communication & 318 & 1.8286 & .04974 & .88701 \\
\hline
\end{tabular}

Knowing the actual working circumstances and developing new understandings are primarily important to respond to emerging conditions and challenges which basically affect the progress of craft industries. The essence of developing responsiveness, collaboration and cohesiveness among the craftspeople in cultural industries enables them to share feelings which eventually result in solidarity, harmony and commitment among the craft community. In these attributes of inside and outside group reflexivity, potters and weavers in Gojjam had drawbacks. Communication practices for clarity of objectives, with feedback and right direction for innovation was negligibly practiced among the craftspeople in Gojjam.

Thus, the results presented so far showed that craftspeople had problems in their practice of frequently sharing information about creativity within and outside, and applying risk free, reflexive and task oriented 
communication. Generally, traditional craft industries failed to access and expose themselves to innovative information through mediated communication. To the worst case, these craftspeople rarely share the knowledge, technical skills and experience they had to their craft-mates and take little or no lesson from the nearby modern industries.

\section{Innovation Implementation in Craft Industries}

The practice of craftspeople engaged in pottery and weaving industries in Gojjam have long historical bases. Their tendency of manufacturing novel products which could add values and satisfy the needs of their customers has been, however, negligible due to failures in copying and adapting from local and international experiences. As a result, most craft industries were less likely to manufacture products with new designs. As presented in Figure 3 below, $42.6 \%$ of potters and weavers did not manufacture new products which are totally different from the current ones. To the other end, $35.3 \%$ craftspeople improved the design of their products from their own learning curve. In product innovation, $68.7 \%$ of potters and weavers did not implement any cost reduction strategy to enhance production efficiency. Only $15.6 \%$ of the craftspeople made little improvements on production efficiency by their own effort.

Novelty in the current product is developed by improving the customers' ease of using it and their satisfaction. The results presented in Figure 3 above revealed that $63.06 \%$ of the craftspeople did not implement innovation at all in the process of making the product. Only $21.9 \%$ made little improvement owing to the long years' of experience they had on pottery and weaving industries. Due to limited opportunities that craftspeople have in accessing modern industrial products, only $8.78 \%$ of potters and weavers attempted to implement innovation by copying products from local and national markets. It can be noted that craft products can be manufactured with some level of novelty if the craftspeople get some sort of technical support. Manufacturing a totally new product, however, requires high creative potentials and perseverance to surmount challenges. It is really cumbersome for weavers and potters to implement radical innovation in their cultural industries. This scenario is indicative to the intention of enhancing their skills which result in product innovation and production efficiency.

The performance of one's craft industry depends much on the capability of a craftsperson in minimizing non-value adding activities, reducing variable costs, eliminating invaluable activities in the process craft making and delivery. $56.1 \%$ of the craftspeople in weaving and pottery craft industry fail to implement innovation so as to eliminate non-value adding activities in production processes. Only $10.1 \%$ weavers and potters in the study area implemented process innovation through adaptation from local and national experiences. Some more craftspeople (27.9\%) also proved that their limited innovations were the results of improvements in the current practice owing to their longer experience in the craft sector.

The results presented in Figure 4 shows that there is absence of attempts to implement innovation among many of the craftspeople in pottery and weaving industries (78.1\%). The innovation implemented in manufacturing processes, techniques and machinery remained unchanged in the practice of increasing output quality (74.5\%). Moreover, innovations on avoiding non-value adding delivery processes (52.5\%) and speed of delivery, logistics (66.0\%) were not implemented. In the rest of the implementations of 
innovation, some weavers and potters replied as their current production process is the improvements made through experience. From this we can learn that the practice of implementing innovations underwent failures in most of weaving and pottery industries in Gojjam. Experience to some extent attributed to the implementation of innovation which adds values to the process of manufacturing ordinary and cultural costumes and materials.

Reforms made to renew the design, appearance, shape, distribution channel, promotion and pricing tactics of craft industries are hallmarks to marketing efficiency and effectiveness. According to $60.4 \%$ of the respondents (see figure 5 below) weavers and potters did not implement any marketing innovations so as to renew the design of the products. They did not make changes on the appearance of the product, shape or volume without changing their basic functional features. Few (8.6\%) of them, however, copy these components of marketing innovation from local and national markets while some others( $26.1 \%)$ implement innovation in their craft industry by improving the techniques through experience.

Craftspeople (24.8\%) have undergone changes in their prior distribution channel through the implementation of innovations imitated from local and national exposures. Most of them (41.4\%), however, did not implement any innovations to renew the distribution channels without changing the logistics process related to product delivery. In addition, $8.6 \%$ of weavers and potters employ renewed product promotion techniques imitated from local strategies whereas $19.0 \%$ made improvements on their own innovative promotion techniques. About $19.0 \%$ craftspeople revised their pricing strategy taking into account their new products and market condition. The majority of the craftspeople, however, are unsuccessful to implement innovative marketing strategies to their crafts.

Craft industries as a small scale business organizations demand efficient organizational structure which implements innovation in their value chain. The practice of weavers and potters entails that they had diverse attempts to implement attributes of organizational innovation at different extents. As can be seen in Figure 6, a significant number of craftspeople never implement attributes of organizational innovation in their industries all along their craft making practices. Some craftspeople (16.0\%) attempted to implement innovation by renewing the routines, procedures and processes employed to perform firm activities by imitating from local and national innovative experiences. About $19.0 \%$ of them also made innovative reforms in their manufacturing process. In the supply management system, $18.4 \%$ and $20.6 \%$ of weavers and potters in the study area implement innovation copying from in-house experiences and improving their own practical exposures in craft industries.

As depicted in figure 6 below, there were negligible practices to realize innovation in their human resource management system using local and international organizational experiences. Hence, the craftspeople had insignificant efforts exerted to introduce innovative experiences in their organizational structure, value chain management, information exchange and coordination within and outside.

Implementing radical innovations, changing extant practices and adapting from local and international markets are proved to be the proposed criteria to investigate innovation implementation. The data collected from sampled potters and weavers revealed (see figure 7) that product, process, and marketing 
and organizational innovation implementations are totally limited. Accordingly, their innovation is mainly based on improving their existing products.

\section{The association of communication and innovation with performance}

A structural equation model was used to evaluate the association between communication and innovation with performance. As depicted in Table 5 below, the performance of craftspeople is significantly influenced by their communication practices and innovation implementation. Their reflexive communication practices which may develop internal and external solidarity among craftspeople, communication safety, frequency of communication on creativity and task communication had significant relations with performance. The implementation of innovation to renew craft products, the renewal of marketing strategies, and organizational innovation significantly contributed to the performance of craftspeople. The association of boundary spanning and process innovation was, however, insignificant with performance.

\section{Table 5. SEM analysis on communication and innovation association with performance}

\begin{tabular}{|llll|}
\hline Manifest variables(for communication and innovation) & Coefficient & Std.err & $p>/ z /$ \\
\hline Constant & $5.0616^{\star \star \star}$ & 0.1757 & 0.000 \\
\hline Reflexivity & $-0.3946^{\star \star \star}$ & 0.1011 & 0.000 \\
\hline Task communication & $0.1381^{\star}$ & 0.0846 & 0.100 \\
\hline Communication safety & $0.2251^{\star \star}$ & 0.1011 & 0.026 \\
\hline Frequency for communication on creativity & $0.1768^{\star \star \star}$ & 0.0531 & 0.001 \\
\hline Boundary spanning & 0.0224 & 0.0712 & 0.753 \\
\hline Product innovation & $0.6486^{\star \star \star}$ & 0.0744 & 0.000 \\
\hline Organizational innovation & $0.2093^{\star \star}$ & 0.0778 & 0.007 \\
\hline Marketing innovation & $0.2242^{\star \star \star}$ & 0.0669 & 0.001 \\
\hline Process innovation & 0.0412 & 0.0769 & 0.592 \\
\hline Dependant variable: performance & & & \\
\hline$\star \star \star$ Significant at 1\%, ** significant at 5\%; significant at $10 \%$ & & \\
\hline
\end{tabular}

\section{Model Fitness Test}

The Root Mean Squared Error of Approximation (RMSEA), the Standardized Root Mean Squared Residual (SRMR) and the Coefficient of Determination (CD) are commonly used parameters to measure the 
goodness-of-fit of the SEM model. The RMSEA, which is an important post optimality test of SEM regression shows that the value in this model is below the threshold level of 0.08 . This test labels the SEM model as fit if the lower bound of the $90 \%$ confidence interval is below 0.05 and the upper bound is above 0.10 . The $p$-value for a test of close fit ( $\boldsymbol{p}$ close) is between 0.994 and 1 , which provides strong evidence for the acceptance of the RMSEA that is below 0.05 at $90 \%$ confidence interval as a model fit indicator. Thus, our SEM model best fit the dataset as it provides the most important model fit statistics (i.e. RMSEA value).

\section{Table 6. Model fitness test of SEM results}

\begin{tabular}{|ll|}
\hline Description & Value for $\mathbf{2 0 1 6}$ \\
\hline Root mean squared error of approximation (RMSEA) & 0.008 \\
\hline Pclose value (Probability RMSEA <= 0.05) & 1.000 \\
\hline Comparative fit index (CFI) & 1.000 \\
\hline Tucker-Lewis index (TLI) & 1.000 \\
\hline Standardized root mean squared residual (SRMR) & 0.000 \\
\hline Coefficient of determination (CD) & 0.280 \\
\hline
\end{tabular}

As it was noted by Bentler (1990), the Comparative Fit Index (CFI) and Tucker-Lewis Index (TLI) values of 1 or closer shows good model fit to the dataset. Accordingly, the SEM model provided CFI and TLI values of 1.00 , see Table 6 . The $C D$, which is the $R^{2}$ of the model, shows perfect fit of the model when it is 1 or $100 \%$. However, for cross sectional data like that of ours, the CD values are often far less than the indicated threshold. Additionally, the SRMR value of zero shows a perfect fit of SEM model while the values of below 0.08 still show better fit of the model. In the above table, the SRMR values of 0.000 shows the goodness of fit of SEM model to our datasets.

\section{Discussion}

\section{Indigenous crafts in Gojjam}

Findings drawn out of the analysis depict that indigenous industries are sources of tangible craft products that realize socio-culturally shaped creative products primarily aimed to address the local needs of customers. These crafts are transferred from generation to generation mainly through family level inheritance. Zhan et al. (2017) consistently revealed that the tradition of manufacturing cultural objects make craft industries sustainable and accumulates socially meaningful material culture all along the generation. Investigating cultural products designed by applying specific cultural knowledge, Chai et al., (2018) confirm the existence of escalated demand for cultural products whereby the design itself is considered as an impetus for cultural development. The exploration by Mamidipudi (2016) similarly capitalizes a tacitly owned socio-technology that craftspeople acquired and habituated is taken as a base 
to theorize craft innovation. The craft making traditional practice in Gojjam, alike other localities, (Dubois, 2008), has limited attribution for craft innovation. These clearly imply that Ethiopia is the unexploited source of traditional craft industries, and pottery and weaving crafts in Gojjam are typical reflections of the cultural creativity of the north-eastern part of the country.

\section{Communication Practices}

The craftspeople asymmetry of communication for creative ideas among themselves and with other emerging industries reveals that they rarely access information on how to implement various innovations and how to share indigenous knowledge and technical skills. Hence, using information to operationalize innovation has been minimally practiced. The failure craftspeople have regarding mediated and interpersonal communication in the process of production, promotion and marketing of their crafts attribute to the minimal implementation of innovation. It is also implied that more than $90 \%$ of the potters and weavers have no or less purposeful communication strategic practices as the crafts are mainly limited to family level. This is against the finding of Evsukova et al. (2017) who suggest activity oriented communication that considers scientific innovation through interpersonal interaction through different channels of communication. Zerfass and Huck(2007), Solomon (2003) and Lin and Chen (2012) confirmed this justifying that the core product of innovation activities is knowledge, and this new knowledge can only be created through interaction between specialists with varying backgrounds of expertise as the cement of innovation activities is communication. The synthesis so far implies the practical relevance of risk free, reflexive and task oriented strategic communication in sharing and implementing innovation. This strengthens the theoretical explanation how communication and innovation are interconnected in indigenous craft industries alike how it works in emerging industries.

\section{Innovation Implementation}

Significant number of weavers and potters has negligible practices of implementing innovation which entails that innovating products, process, marketing and organizational systems are implemented by improving their own prior experiences. This relatively attributes to change product and marketing aspects as compared to other facets of innovation. The trifling implementation of innovation from local and national markets and dearth of radical innovation depict as the practice towards innovation is stagnant which typically characterizes traditional evolutionary innovation. This is consistent with the finding of Grobar (2017) revealing that high value-adding and hybrid crafts combine traditional production methods with locally, nationally and internationally available modern design and branding stemmed from strengthening links between craft production and revenue in tourism industry. Banks' (2010) partially contradicts with Grobar(2017) as the former addresses controlling the quality of products that express region-specific features made from local materials evoke the emotional experiences of local people and sometimes attractive to foreigners. In the study by Dubois (2008), it is posited that crafts are a mirror of the cultural diversity in Ethiopia resulted from a combination of creativity, culture, heritage, and craftspeople's environment. Hence, findings practically imply that weaving and pottery craft industries in 
the study area have limited attempts to introduce innovative experiences in their organizational structure, value chain management, information exchange and coordination within and outside.

\section{The association of communication and innovation with performance}

The performance of weaving and pottery industries is significantly associated with the frequency of purposeful communication on creativity, communication safety and reflexive communication practices that develop internal and external solidarity among craftspeople. Task communication has moderate level of association with performance. Craftspeople have failures to break socio-cultural boundaries and share information within and out in that its association with performance is insignificant. KPMG's (2016) investigation has compliance as it confirms the contribution of having stronger communication links with creative industries for enhanced innovations as compared to those firms that spend double the average amount on creative products. Leenders et al. (2003) revealed that communication defects in craft teams have been due to communication media richness and communication frequency related problems which has in turn become the first and foremost determinant of performance.

The efforts exerted to manufacture novel products, renew marketing strategies and improve organizational systems have significant relations with performance while implementing process innovation has insignificant association with craftspeople's performance. This finding is consistent with what Xin et al.(2010) confirm that technologically innovative products have statistically significant positive effect on performance. Different from the current study, the investigation of KPMG (2016) proves that processes of craft innovation have always driven breakthroughs that have passed into other fields. Thus, it is implied that innovation significantly influence performance, and its meditational role to the association between communication and business performance is pertinent. In brief, weaving and pottery industries in Gojjam are declining mainly due to lack of marketing channel and promotion related facets of strategic communication and innovation implementation.

\section{Conclusions}

Endeavors to communicate safely and to accomplish tasks effectively are minimal as creating reflexive orientations is limited to family level. This is contrary to integrating craftspeople with non-craft community as an opportunity for craft sustainability and increasing the number of craftspeople joining these industries. Craftspeople have minimal practice and limited exposure to use both mediated and interpersonal communications that help accessing information on creativity and innovation. It is, thus, practical to conclude that the trend of exchanging indigenous knowledge and technical skills in cultural industries are limited, and the craftspeople are not determined to share information breaking extant boundaries. This entails as the practices towards routinization and cross-fertilization of innovative ideas and associated potentials are suppressed owing to communication related drawbacks.

Implementing innovation through copying and adapting creative ways ranging from local, national and international experiences to breakthrough inventions, thus, account adding new insights to craft products. Practically, craft industries in Gojjam have implemented little innovations just out of minor improvements 
made on their existing product, process, marketing and organizational indigenous innovation implementation. This generally failed to capacitate craftspeople towards radical novelty that could make the industries highly competitive. The significant association of craftspeople's communication practices and innovation implementation with their performance by and large implies the practical contribution of consistent, risk free, reflexive and task-oriented communication that would in turn attribute to renew products, improve organizational system and form strong marketing channel and promotion. It is hence drawn that the innovation of craft industries has been basically influenced due to limited communication enclosed predominantly at family level.

Hence, craftspeople should look inward, be open-minded and purposeful to share information and their indigenous crafting skills to non-craft community and with nearby emerging industries. Through these interactions, interlocutors could generate and implement innovative ideas and add new insights to the current practice by cross-fertilizing and routinizing inventiveness in everyday craft improvement. They should have access to media so that national and international innovative experiences could be easily shared to strengthen indigenous endeavors of adding values to products, processes and marketing strategies which pave the way to innovations unique to craft industries. Stakeholders need to capacitate the communication practices and innovation implementation of local craft industries. They should play key roles in organizing cooperatives and associations through which craftspeople can buy inputs of production, promote and supply their products by breaking longer market channels. Establishing incubation centers at clustered localities might facilitate the technical supports to be rendered. This would create opportunities to adapt and copy from local, national and international experiences that would help heading towards radical innovations and sustainable development.

\section{Limitations and suggestions for future studies}

The present study was conducted using more quantitative techniques of data collection and analysis. It has limitations to explore the local innovative knowledge and skills that characterize weavers and potters in Gojjam much in-depth. The extant limited innovative practices adapted from local and national markets, the improvements and new values added to the experience of craftspeople need to be thoroughly explored. We suggest for future researchers to narrowly explore the indigenous practices in this respect describing how these innovation implementations have been conducted. By relating the weaknesses and strengths the craftspeople have, it may be suggestive to explore how these gaps can be bridged by taking the experience of emerging creative industries and how craft innovations could contribute to the modern industries. The study could be also better done by designing intervention mechanisms which can foster the communication and innovation practices of craftspeople.

\section{Declarations}

\section{Availability of data and materials}

The datasets used and/or analysed during the current study are available from the corresponding author on reasonable request. 


\section{Competing interests}

The authors declare that they have no competing interests.

\section{Funding}

This study was funded by Institute of Haddis Alemayehu culrure studies, Debre Markos University, Ethiopia.

\section{Authors' contributions}

WMD has research experience in the area of creativity and innovation. As a principal researcher he conducted the data collection, analysis and interpretation in the area of communication and innovation. The overall write up and editing was done by him

GAM: As an expert in the area of business management focused on the innovation and business performance of craft industries

TAM: She is an expert in the area of communications studies and investigated the role of communication in the craft industries. Detailed explorations in the data collection, analysis and interpretation of communication related problems were carried out.

\section{Acknowledgements}

The researchers are grateful to Institute of Haddis Alemayehu Culture Studies, Debre Markos University for funding this research.

\section{References}

1. Amabile, T M.(2012). Componential theory of creativity.Sage Publications Harvard Business School, Encyclopedia of Management Theory (Eric H. Kessler, Ed.)

2. Backer, T.E. \& Rogers, E.M. (1998).Diffusion of innovations theory and work-site AIDS programs. Journal of Health Communication, 3, 17-29.

3. Banks, M. (2010).Craft labor and creative industries. International Journal of Cultural Policy, 16(3), 305-321, DOI: 10.1080/10286630903055885

4. Bentler, P. M. (1990). Comparative fit indexes in structural models. Psychological Bulletin, 107(2), 238-246. http://dx.doi.org/10.1037/0033-2909.107.2.238

5. Central Statistics Agency (2007). Compilation of economic statistics in Ethiopia, Addis Ababa

6. Chai, , Shen, D., Bao, D. \& Sun, L. (2018). Cultural product design with the doctrine of the mean in confucian philosophy. The Design Journal, 21(3), 371-393. 10.1080/14606925.2018.1440842

7. Croes, R. and Vanegas, M.(1998). Co-integration and causality between tourism and poverty reduction. Journal of Travel Research, 47(1), 94-103 
8. Crush, J., \&Peberdy, S. 1998. Trading place: cross-border traders and the South African Informal Sector.Cape Town: Idasa.

9. Dessie,W.M. and Ademe,A.S.(2017). Training for creativity and innovation in small enterprises in Ethiopia. International Journal of Training and Development 21(3), pp224-234,doi:

$10.1111 /$ ijtd.12107

10. Dubois, J. (2008). Roots and flowerings of Ethiopia's traditional crafts. A UNESCO publication for the Ethiopian millennium UNESCO, Addis Ababa office

11. Eisenberg, ,Gerlach R, \&Handke, C.(2006). Cultural industries: The British experience in international perspective. Humboldt, University Berlin, Available: http://edoc.hu-berlin.de

12. Embassy of Japan in Ethiopia (2007).Study on the handicraft industry in Ethiopia. Embassy of Japan in Ethiopia, Addis Ababa, https://www.et.emb-japan.go.jp/Eco_Research_E.pdf

13. Evsukova,V. T., Kotelnikova,V., Evdokimova,V.N., and Germasheva, M.T. (2017). Scientific innovation and its representation in discourse.European Research Studies, 20(1), 319-336

14. Fidler,L. \&A. Johnson,J. D. (1984). Communication and innovation implementation.Academy of Management Review, 9(4), 704-711.

15. Finneran, N.(2007). The Archaeology of Ethiopia.Routlage: London and New York.Gezahegn, A., Chamberlin J., Moorman, Kassu,W.\& Zhang, X.( 2010). Infrastructure and cluster development: A case study of handloom weavers in Ethiopia. Journal of Development Studies, 47(12):1869-1886DOI: 10.1080/00220388.2011.579112

16. Girum, E. (2011). Indigenous knowledge amongShiroMedaDorzecommunity: the case of weaving. National Archives and Library Agency, Addis Ababa University, http://hdl.handle.net/123456789/2752

17. Grobar, L. M. (2017). Policies to promote employment and preserve cultural heritage in the handicraft sector. International Journal of Cultural Policy, 25(4), 1-13. doi:10. 1080 / 10286632.2017 .1330887

18. Gunday, G., Ulusoy, G., Kilic, K.\&Alpkan, L.(2011). Effects of innovation types on firm performance.International Journal of Production Economics, 133(2011), 662-676

19. Hagedoorn, j. and Cloodt, M.(2003). Measuring innovative performance: is there an advantage in using multiple indicators? Research Policy. 32 (2003), 1365-1379

20. Hartley, J. (2007). The evolution of the creative industries - Creative clusters, creative citizens and social network markets. In Proceedings Creative Industries Conference, Asia-Pacific Weeks, Berlin

21. Hirst, G., \& Mann, L. (2004). A model of R\&D leadership and team communication: the relationship with project performance. Research and Development Management, 34(2), 147-160. doi:10.1111/j.1467-9310.2004.00330.x

22. Hoegl, M., \&Gemuenden, H. G. (2001). Teamwork quality and the success of innovative projects: a theoretical concept and empirical evidence. Organization Science, 12, 435449.http://dx.doi.org/10.1287/orsc.12.4.435.10635 
23. Hofverberg, H. (2010). Dorze weaving in Ethiopia: A model of education for sustainable development (Thesis). Retrieved from http://urn.kb.se/resolve? urn=urn:nbn:se: uu:diva-155268

24. Hughes, C.(2012). Gender, craft labor and the creative sector. International Journal of Cultural Policy, 18(4), 439-454, DOI: 10.1080/10286632.2011.592187

25. Karabulutu, A.T.(2015). Effects of Innovation Strategy on Firm Performance: A Study Conducted on Manufacturing Firms in Turkey. Procedia - Social and Behavioral Sciences,195 ( 2015 ), $1338-1347$

26. Kilic, K., Ulusoy, G., Gunday, G., \&Alpkan, L. (2015). Innovativeness, operations priorities and corporate performance: An analysis based on taxonomy of innovativeness. Journal of Engineering and Technology Management, 35,115-133, doi:10.1016/j .jengtecman. 2014.09.001

27. Klynveld Peat Marwick Goerdeler (2016). Innovation through craft: opportunities for growth. Annie Warburton, Creative Director, Crafts Council, a Swiss entity.

28. Kotelnikova, E. V. (2014). Study of scientific-innovative discourse of intercultural communication in the cognitive aspect: Monograph. Rostov-on-don, Publishing House of Rostov State University of Economics (RINH).

29. Leenders, R., Th, A.J., van Engelen, J.M.L. and Kratzer, J. (2003). Virtuality, communication, and new product team creativity: social network perspective, Journal of Engineering and Technology Management, Vol. 20 Nos 1-2, pp. 69-92

30. Lin, H. (2007). Knowledge sharing and firm innovation capability: an empirical study. International Journal of Manpower, 28(3/4), 315-332, doi:10.1108/01 437720710755272

31. Lin, R. \& Chen, C. (2012). A discourse on the construction of a service innovation model: focus on the cultural and creative industry park. National Taiwan University of Art, Taiwan, R.O.C.

32. Livingstone, S. et al. (2009).Parental mediation of children's internet use.Journal of Broadcasting \& Electronic Media, 52(2009), 581-599

33. Mamidipudi, A.(2016). Towards a theory of innovation in handloom weaving in India( PhD dissertation), Maastricht, Netherlands

34. Md-Saad, S., Majid, I. A. , Jano, Z. and Md-Nordin, S.( 2014). Examining the impact of team communication practices in innovative research and development (R\&D) teams: early findings. Journal of Educational and Social Research, 4(4),177-184

35. Messele, K.(2013). Competitiveness model development for Ethiopian traditional fashions in the global market (Unpublished thesis), Addis Ababa University, Ethiopia

36. Mugavero, L. \&Vidale, M.(2006). The helmand polychrome wares as skeuomorphs: interlacing pottery making, painting and basketry. Istitutoltaliano per l'Africa e l'Oriente(ISIAO), 56( 4), 433-437

37. Organization for Economic Cooperation and Development (2005). The measurement of scientific and technological activities proposed guidelines for collecting and interpreting technological innovation data. Organization for Economic Co-operation and Development, Eurostat 
38. Peeters, T.J.G. (2010). Industries, firms, competitive dynamics, and competitive advantage Cultural Industries, Culture Clusters \& Metropolitan areas.Tilgurge University, KitijaVasiljeva.

39. Phillipson, D.W., (2005). African archaeology (3rd edition), https://www.pia-journal. co.uk/ articles/ $10.5334 /$ pia.282

40. Sarat, A. (2016). Editorial. Law, Culture and the Humanities, 12(3), 465465.doi:10.1177/1743872116629742

41. Sennett, R. (2008). The craftsman, London: Penguin

42. Shumetie, A. and Mihret, W. (2020). Effect of creativity and innovation based training on small enterprises' performance: evidence from Ethiopia, J. Innovation and Sustainable Development, Vol. 14, No. 4, pp.375-396.

43. Solomon, W.(2003). The state of small-scale industries in Ethiopia: problems and policy issues. The Ethiopian Economy: Structure, Problems and Policy Issues. 1991, 171-182

44. Tufte,T. \&Mefalopulos,P.(2009). Participatory communication: a practical guide. Washington DC, World Bank

45. United Nations Industrial Development Organization (2002).Industrial development report 20022003: competing through innovation and learning (Revenue No. 02.II.B.13)

46. Vinodrai, T. \&Gertler, M. S. (2006). Creativity, culture and innovation in the knowledge-based economy opportunities and challenges for Ontario program on globalization and regional innovation systems. Munk Centre for International Studies \& Department of Geography, University of Toronto.

47. Wayessa, S. B.(2011). The technical style of Wollega pottery making: An ethnoarchaeological study of Oromo potters in southwest highland Ethiopia. The African Archaeological Review, 28(4) , 301326

48. Wherry, F. (2008). Global markets and local crafts: Thailand \& Costa Rica compared. Johns Hopkins University Press, Baltimore

49. World Bank. (2008) Linking Education Policy to Labor Market Outcomes (Washington, DC: World Bank).

50. Xin et al. (2010).Effects of innovation types on firm performance. International Journal of Production Economics, 133(2), 662-676

51. Yamane, T.(1967). Statistics, an introductory analysis (2nd Ed), New York: Harper and Row

52. Zerfass, A.,Verčič, D., Nothhaft, H., \&Werder, K.P.(2018). Strategic communication: defining the field and its contribution to research and practice. International Journal of Strategic Communication, 12(4), 487-505, https://doi.org/10.1080/15 53118x.2018.1493485.

53. Zerfass,A. \&Huck,S. (2007). Innovation, Communication, and Leadership: New Developments in Strategic Communication. International Journal of Strategic Communication, 1(2), 107-122, DOI: 10.1080/15531180701298908

54. Zhan, X., Walker, S., Hernandez-Pardo, R. \& Evans, M.(2017). Craft and sustainability: potential for design intervention in crafts in the Yangtze River Delta, China. The Design Journal, 20(1), S2919- 


\section{Figures}

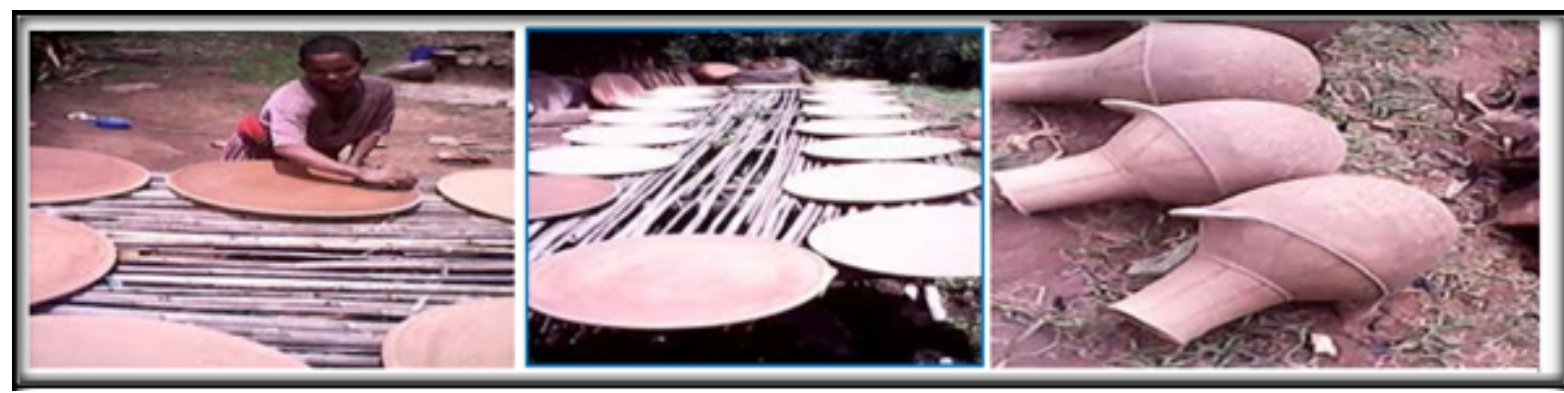

\section{Figure 1}

A potter and her sample crafts products taken from Quarit and Debre Elias Districts

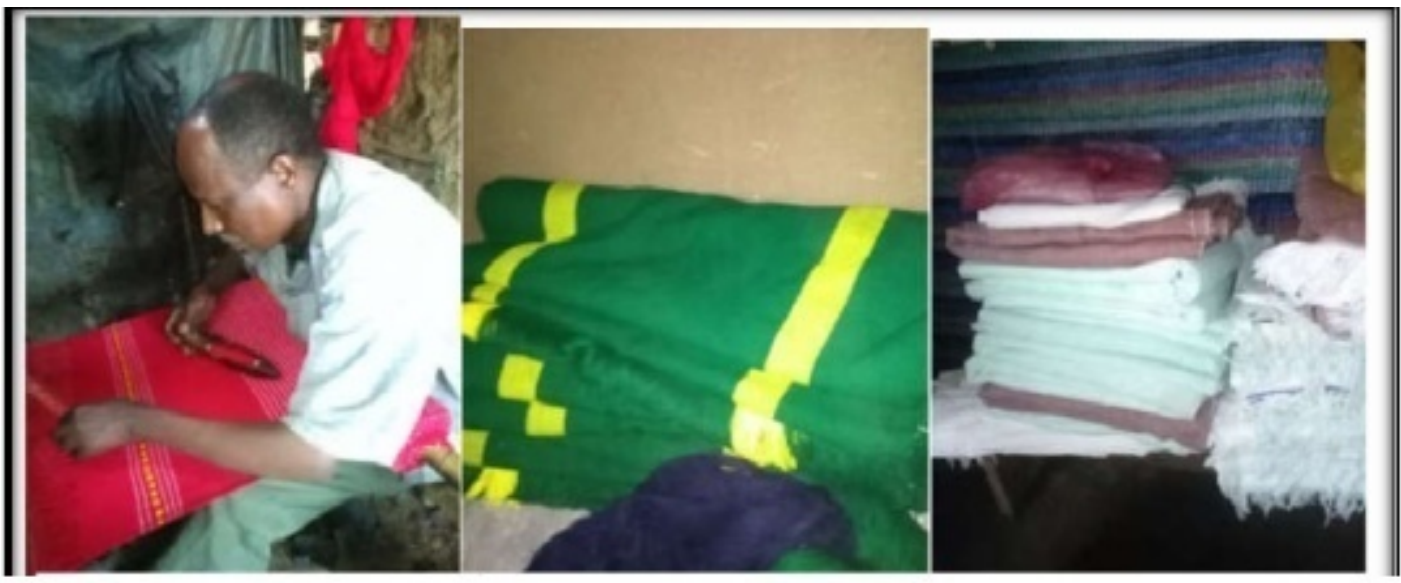

Figure 2

A weaver and sample tradition clothes manufactured and Sekela and Machakel Districts

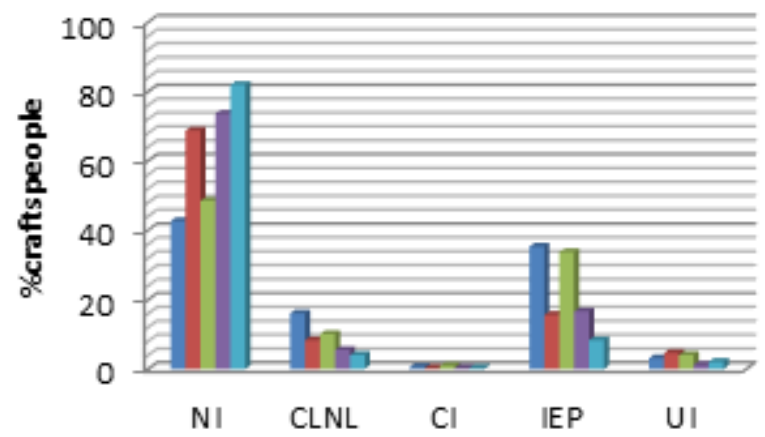

Reniewing manufacturing quality

Minimiz ing manufacturing cost

Renuing newness ease of use

- Renuing technical specifications

nenuing totally different

ways of innovations are implemented

Figure 3

craftspeople product innovation implemented 


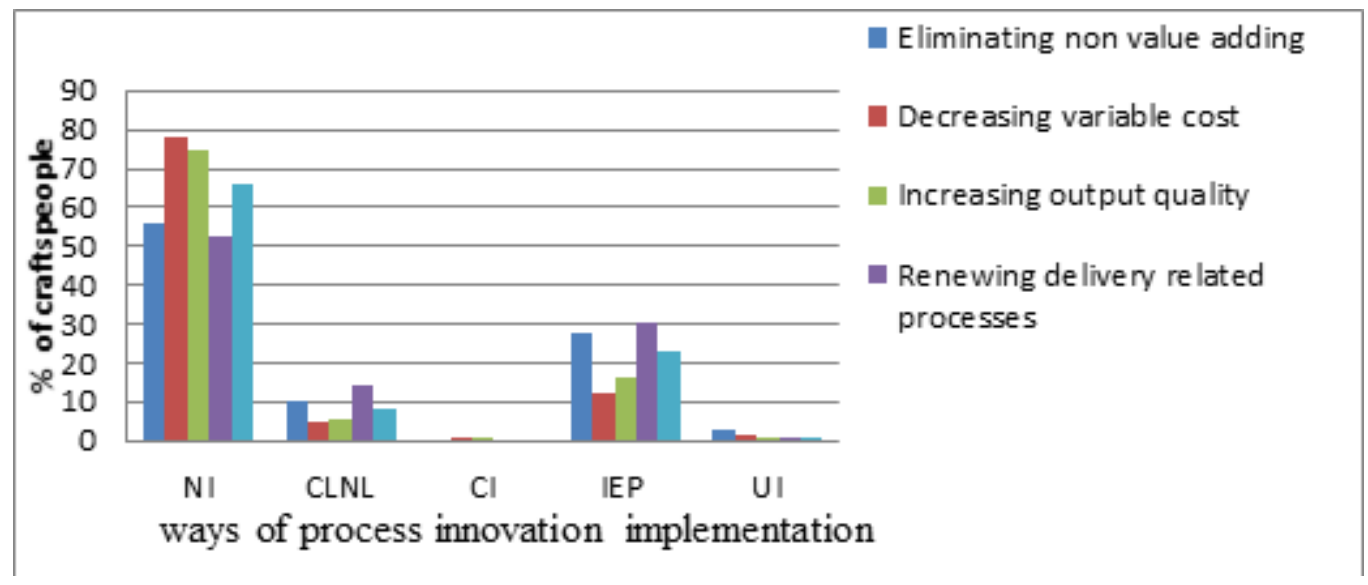

\section{Figure 4}

Craftspeople process innovation implementation

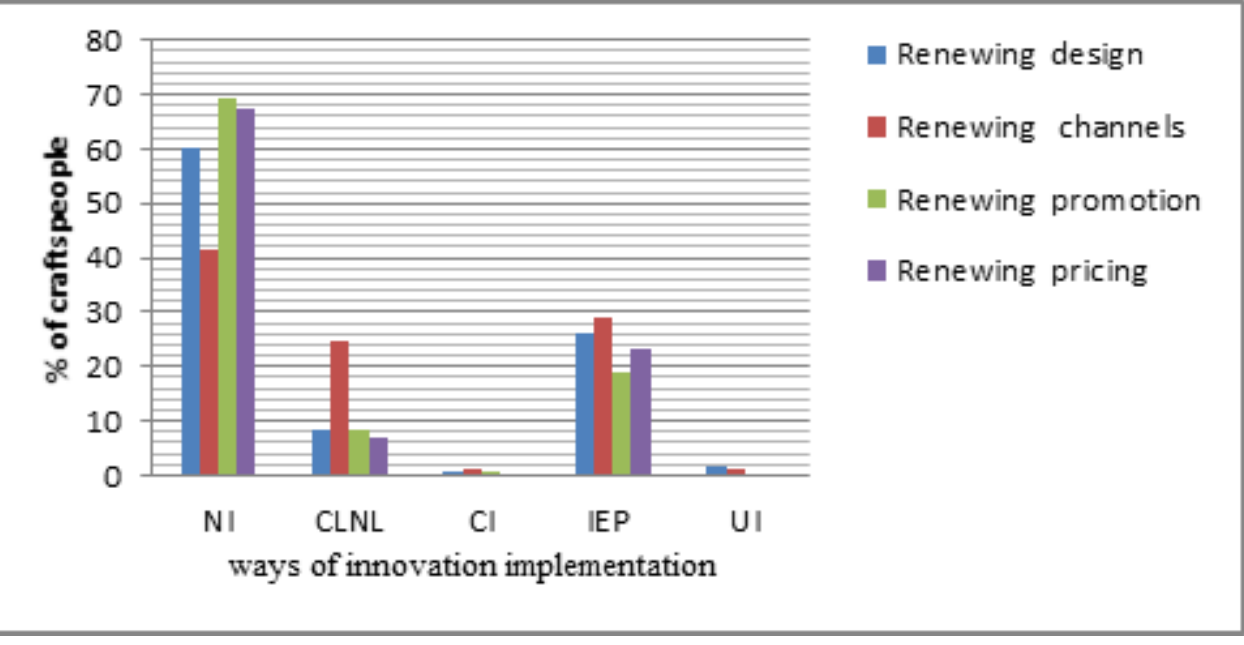

\section{Figure 5}

Marketing innovation implementation

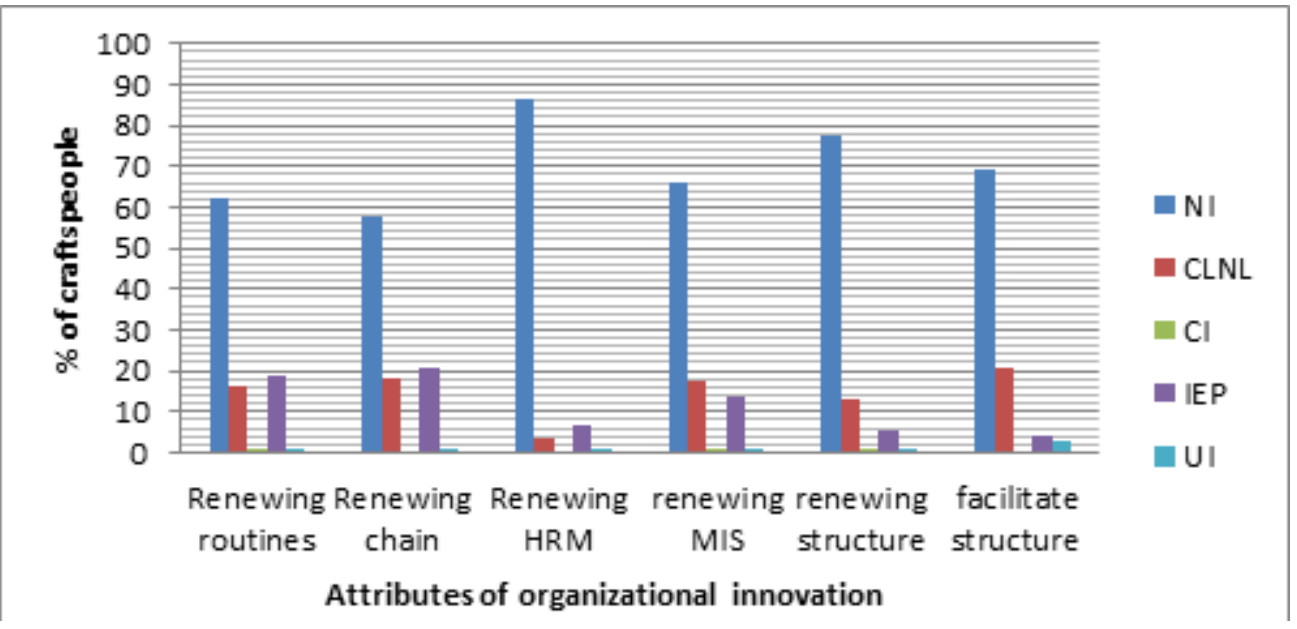

Figure 6 
craftspeople implementation of organizational innovation

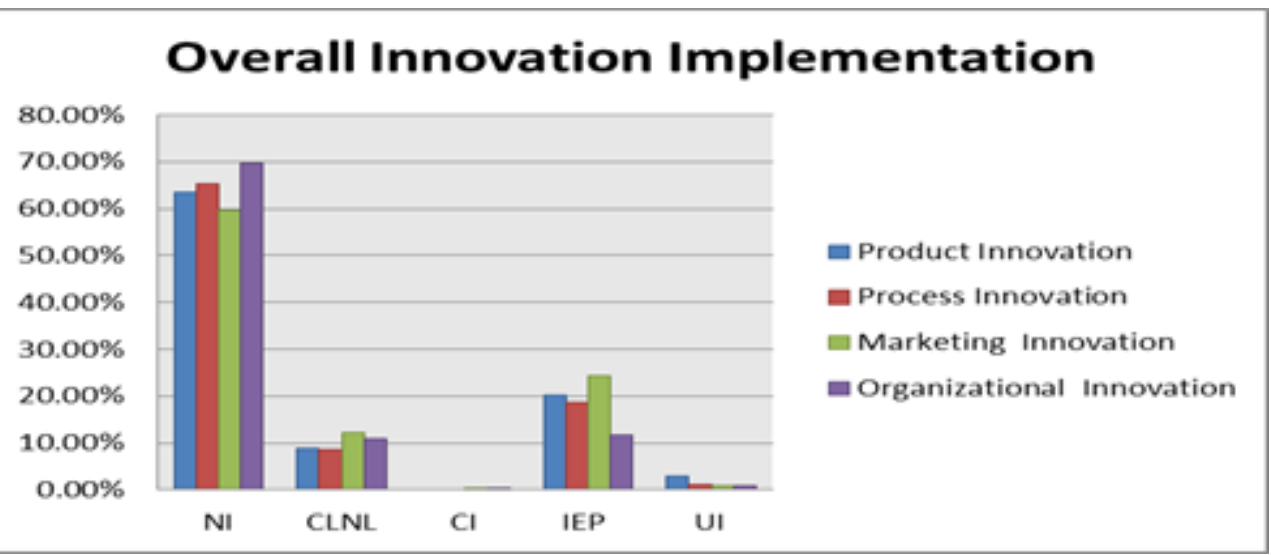

Figure 7

Summary of innovation performance of sampled craftspeople 